\title{
Analysis of tRNA ${ }^{\text {Cys }}$ processing in the absence of CCAase in Bacillus subtilis
}

\author{
Juan Campos Guillén ${ }^{1}$ • Jackeline Lizzeta Arvizu Gómez ${ }^{2}$ • George H. Jones ${ }^{3}$ • José Luis Hernández Flores ${ }^{4}$. \\ Miguel Angel Ramos López ${ }^{1}$. Andrés Cruz Hernández ${ }^{5}$. Sergio Romero Gómez ${ }^{1}$
}

Received: 27 September 2018 / Accepted: 8 March 2019 / Published online: 12 April 2019

(C) Sociedade Brasileira de Microbiologia 2019

\begin{abstract}
In Bacillus subtilis, the tRNA ${ }^{\text {Cys }}$ lacks an encoded CCA $3^{\prime}$ end. To gain insight into the role of CCAase and RNases in tRNA ${ }^{\text {Cys }}$ processing, several mutant strains were generated. Northern blot and RT-PCR results suggest that enzymes other than CCAase can participate in CCA addition at the $3^{\prime}$ end of the immature tRNA ${ }^{\mathrm{Cys}}$.
\end{abstract}

Keywords Bacillus $\cdot$ tRNA ${ }^{\text {Cys }} \cdot$ CCAase

In Bacillus subtilis, as in other bacteria, some tRNA genes encode the $3^{\prime}$ CCA, which is essential for tRNA function in aminoacylation, while for other tRNAs the 3' CCA must be added post-transcriptionally [1]. Such as the case for tRNA ${ }^{\text {Cys }}$, which is one of the 26 tRNAs without an encoded CCA in B. subtilis. tRNA ${ }^{\mathrm{Cys}}$ is present in single copy in the genome and is located at the distal end of the $\operatorname{trn} D$ operon, which also contains genes for $5 \mathrm{~S}, 16 \mathrm{~S}$, and $23 \mathrm{~S}$ ribosomal RNAs and genes for 16 other tRNAs [2]. In B. subtilis, the endo- and exonucleolytic pathways for tRNA ${ }^{\mathrm{Cys}}$ maturation have been investigated and in the case of RNase Z, an endoribonuclease

Responsible Editor: Lucy Seldin.

Electronic supplementary material The online version of this article (https://doi.org/10.1007/s42770-019-00075-5) contains supplementary material, which is available to authorized users.

Juan Campos Guillén

juan.campos@uaq.mx

1 Facultad de Química, Universidad Autónoma de Querétaro, Cerro de las Campanas s/n, 76010 Querétaro, QRO, Mexico

2 Secretaria de Investigación y Posgrado, Centro de Innovación y Transferencia de Tecnología (CENIT2), Universidad Autónoma de Nayarit, Tepic, Mexico

3 Department of Biology, Emory University, Atlanta, GA 30322, USA

4 Laboratorio de Bioseguridad y Análisis de Riesgo, Departamento de Ingeniería Genética, Centro de Investigación y de Estudios Avanzados del IPN, 36824 Irapuato, GTO, Mexico

5 Escuela de Agronomia, Universidad De La Salle Bajío Campus Campestre, León, GTO, Mexico that processes the 3' end of tRNAs lacking an encoded CCA, tRNA $^{\text {Cys }}$ appeared to be correctly processed when the enzyme was depleted [3]. On the other hand, the exoribonuclease RNase PH, which is an important component of the exonucleolytic maturation of CCA-containing tRNA precursors, showed accumulation of species 3 or 4 nucleotides longer from the discriminator base for tRNA ${ }^{\mathrm{Cys}}$ in vitro. In contrast, in vivo analysis of $r p h$ single mutants or double mutants constructed by mutating the genes for other RNases involved in mRNA decay, such as PNPase, RNase R, or YhaM showed correct processing of tRNA ${ }^{\mathrm{Cys}}$ [4]. In vitro studies revealed that RNase $\mathrm{Z}$ and RNase PH activities are inhibited by the presence of a CCA motif at the end of the acceptor stem [3, 4].

The CCA-adding enzyme, tRNA nucleotidyltransferase or CCAase, is the enzyme responsible for the maturation of tRNAs whose genes do not encode those three bases, and for the repair of tRNAs with damaged $3^{\prime}$ ends. CCAase is not an essential enzyme in Escherichia coli as all its tRNA genes encode the CCA $3^{\prime}$ end and other enzymes such as PNPase and poly(A) polymerase can participate in the repair of tRNA $3^{\prime}$ ends. However, since some $B$. subtilis tRNA genes do not encode the $3^{\prime}$ CCA, the addition of CCA to the $3^{\prime}$ end of those tRNAs is expected to be dependent on CCAase.

We previously examined this presumed dependency in B. subtilis using a conditional CCAase mutant containing an inducible $c c a$ gene [1]. Analysis of tRNA ${ }^{\text {Cys }}$ species in the mutant in the absence of the inducer showed the accumulation of a shorter form of tRNA ${ }^{\text {Cys }}$. It is likely that this species is tRNA ${ }^{\text {Cys }}$ lacking the 3' CCA. This shorter species was only observed in the conditional mutant when RNase $\mathrm{R}$ was absent. The shorter species was not observed in the uninduced strain 
in the absence of PNPase. Interestingly, some RT-PCR products from these strains showed different $3^{\prime}$ additions in position 71 of tRNA ${ }^{\text {Cys }}$, such as...ccu ccu $_{71} \mathrm{AAA}, \ldots \mathrm{ccu}_{71} \mathrm{CCAAA}$, or ....ccu ${ }_{71} \mathrm{CAAA}$ when PNPase, RNAse R, or CCAase were absent [1]. These results suggest that, as in E. coli, B. subtilis has alternative pathways for tRNA ${ }^{\mathrm{Cys}}$ maturation or repair.

In a subsequent study, performed under conditions of oxidative stress induced in B. subtilis by exposure to mercury [5], a shortened tRNA ${ }^{\mathrm{Cys}}$ species represented around $10 \%$ of total tRNA ${ }^{\text {Cys }}$ in the wild-type strain [6], while that in the absence of PNPase the level of the shorter species increased to ca $70 \%$ of total tRNA ${ }^{\text {Cys }}$. All these observations suggest a complex relationship between $c c a$, pnp, rnr, and perhaps other, unidentified, enzymes in the maturation or repair of tRNA ${ }^{\mathrm{Cys}}$ in B. subtilis.

In the present study, we report tRNA ${ }^{\text {Cys }}$ processing in a $c c a$ mutant strain and in $c c a$ mutants in combination with mutations is various RNase genes ( $p n p, r n r, r p h, y h a M$, and Pspac:rnz), including several RNases that have not been examined previously in the $c c a$ mutant. We observed a low-level accumulation of a shorter species of tRNA ${ }^{\mathrm{Cys}}$ in the $c c a$ mutant and a much higher level of accumulation of this shorter species in a cca pnp double mutant. Moreover, the analysis of tRNA $^{\text {Cys }} 3^{\prime}$ extensions by RT-PCR revealed the accumulation of extension products when CCAase was absent. These results confirm the complex interaction between CCAase and enzymes that are specifically involved in tRNA ${ }^{\text {Cys }}$ maturation and provide evidence for the participation of other RNases in the maturation or repair process.

To construct the $c c a$ disruption, a 485-base-pair EcoRVPstI fragment in the $c c a$ coding sequence was replaced with a spectinomycin resistance gene, generating plasmid pIO2. Plasmid pIO2 DNA was linearized with ScaI and used to transform $B$. subtilis strain BG1 to spectinomycin resistance, with selection for growth on $200 \mu \mathrm{g} / \mathrm{ml}$ spectinomycin. The disruption of the $c c a$ gene was confirmed by PCR using a 5' primer whose sequence begins $\sim 480 \mathrm{bp}$ upstream of the $c c a$ gene (TTCCGCAATATCGCTGGCAAAACG) and a 3' primer that is complementary to a sequence $\sim 180 \mathrm{bp}$ upstream of the $c c a$ stop codon (TCAAGATCCTTAAGGCTTTT GATCG). The expected $2.5 \mathrm{~kb}$ fragment was obtained (data not shown). The resulting strain was designated BG254 [7]. The B. subtilis prototroph PY79 was used as the wild-type strain and a $c c a$ mutant was constructed by transformation of PY79 with genomic DNA from the BG254 strain, producing strain GOB3. GOB3 was transformed with total DNA from a strain with the resistance cassette [8], or with DNA from a tetracyclineresistant $r n r$ deletion mutant [9], DNA from a chloramphenicol-resistant $r p h$ deletion mutant [4] or with DNA from a phleomycin-resistant yhaM deletion mutant [10]. GOB3 was also transformed with DNA from a Pspac:rnz strain and to obtain higher repression of the spac promoter, this strain was transformed with plasmid pMAP65, which carries further copies of the LacI repressor [3, 11]. Single or double mutant strains were recovered in LB medium with the appropriate antibiotics.

For RNA isolation, all strains were grown at $37{ }^{\circ} \mathrm{C}$ in LB medium and aliquots were withdrawn during the exponential phase (100 Klett units). Pspac:rnz was grown with or without IPTG at $1 \mathrm{mM}$. Cells were harvested and cell pellets were resuspended in $0.3 \mathrm{ml}$ of $0.3 \mathrm{M}$ sodium acetate, $\mathrm{pH} 8.8$, $10 \mathrm{mM}$ EDTA, and $3 \mathrm{mg}$ lysozyme $\mathrm{ml}^{-1}$ and were incubated at $37^{\circ} \mathrm{C}$ for $10 \mathrm{~min}$. Samples were subjected to two extractions with equal volumes of phenol equilibrated with the same buffer and vortexed three times for periods of 30,60 , and $60 \mathrm{~s}$ with 1-min intervals between each step. After centrifugation for $15 \mathrm{~min}$, the aqueous phase was transferred to new tubes containing $0.3 \mathrm{ml}$ of phenol, vortexed for $60 \mathrm{~s}$, and centrifuged for $10 \mathrm{~min}$. The aqueous layer was transferred to new tubes, mixed with 2.5 volumes of ethanol, and left on ice for $2 \mathrm{~h}$. Total nucleic acids were recovered by centrifugation for $15 \mathrm{~min}$. The pellet was dissolved in $60 \mu \mathrm{l}$ of $0.3 \mathrm{M}$ sodium acetate ( $\mathrm{pH}$ 8.8). Nucleic acids were reprecipitated with 2.5 volumes of ethanol, left on ice for $3 \mathrm{~h}$, and recovered by centrifugation for $15 \mathrm{~min}$. Samples were treated with DNase as described by the manufacturer (Invitrogen) and RNA was reprecipitated as above $[1,9]$.

Northern blot analysis of tRNA ${ }^{\mathrm{Cys}}$ was done following the recommendations from the NorthernMax Protocol (Ambion). tRNAs were separated on $15 \%$ denaturing polyacrylamide gels. The probe used to detect tRNA ${ }^{\text {Cys }}$ was $5^{\prime}$-GGTT TTGCAGACCTCTGCCTTAC-3' (complementary to nucleotides 18 to 40 of the mature tRNA ${ }^{\mathrm{Cys}}$ ), which was $5^{\prime}$-endlabeled using $\mathrm{T} 4$ polynucleotide kinase (Invitrogen) and $\left[\gamma-{ }^{32} \mathrm{P}\right]$ ATP. To control for RNA loading in Northern blot analyses of tRNA, membranes were stripped and probed with an oligonucleotide derived from the sequence of the 5S rRNA gene, 5'-GGAACGGGTGTGACCTCTTCGCCATCATCA$3^{\prime}$. Quantification of radioactivity in bands on Northern blots was done with a Storm 860 PhosphorImager (Molecular Dynamics) and the digital image was analyzed with Image Quant (Bio-Rad). The RT-PCR strategy for the analysis of 3' extensions to tRNA ${ }^{\mathrm{Cys}}$ was as previously described $[1,9]$. Total RNA (200 ng) was ligated to $200 \mathrm{ng}$ of a hybrid RNA-DNA anchor oligonucleotide [pUUUAACC GCATCCTTCTCT (Dharmacon RNAi Technologies, Thermo Scientific, RNA shown in italics) in $20 \mu \mathrm{l}$ using 40 units of T4 RNA ligase (Amersham Pharmacia Biotech). Two microliters of the ligation reaction mixture were used as the template for reverse transcription-PCR using the Superscript one-step RT-PCR system (Invitrogen), as outlined by the manufacturer. The primers for the reverse transcription reaction were as follows: 5'-AATTCCAAGAATTC GAGAAGGATGCGGTTAAA-3' (primer A, Fig. 2) or 5'AATTCCAAGAATTCGAGAAGGATGCGGTTAAA 
AATA-3' (primer B, Fig. 2). The primer used for PCR was 5'TCCAAAGGCGGCATAGCCAAG-3' (primer C, Fig. 3). To analyze 3' CCA addition, RT-PCR products with primers A and $\mathrm{C}$ from $c c a$ and $c c a$ pnpA mutant strains were cloned into pGEM-T Easy (Promega). The clones obtained were analyzed to select those with inserts of different sizes and these inserts were sequenced.

As previously, we focused here on $\mathrm{tRNA}^{\mathrm{Cys}}$ as a model for tRNAs without encoded CCA ends to study tRNA processing in the absence of CCAase and other RNases (pnp, rnr, rph, yhaM, and Pspac:rnz). We examined tRNA ${ }^{\text {Cys }}$ in vivo processing by Northern blot analysis (Fig. 1). The results in Fig. 1 reveal that, as observed previously [1], there are two major populations of tRNA ${ }^{\text {Cys }}$ species accumulated in the absence of CCAase. One of these has a mobility identical to the only major population of $\mathrm{tRNA}^{\mathrm{Cys}}$ observed for the wild-type strain (wt), which we conclude is the mature tRNA ${ }^{\text {Cys }}$ species. The other smaller population of tRNA ${ }^{\text {Cys }}$ migrated slightly ahead of the mature species (see e.g., the lane representing $\Delta c c a$ ). Quantitative analysis of data from at least three independent experiments showed that the population of shorter tRNA ${ }^{\text {Cys }}$ represented $5.3 \pm 1.5 \%$ and the population of mature tRNA ${ }^{\text {Cys }}$ represented $94.7 \pm 2.5 \%$ of total $\mathrm{tRNA}^{\text {Cys }}$ detected by Northern blot analysis (supplementary data). The rph and yhaM single mutations had no effect on the processing and only a major population of tRNA ${ }^{\text {Cys }}$ was observed. The shorter tRNA ${ }^{\text {Cys }}$ species was not observed in mutants containing CCAase but lacking PNPase ( $p n p A)$ or RNase R ( $r n r)$, nor in the double mutant lacking the genes for both these RNases (data not shown).

The results obtained for the double mutants ( $r p h, y h a M$, and $r n r$ in combination with $c c a$ ) were similar to those observed for the cca mutant alone (Fig. 1, left panel). Quantitative analysis of data from at least three independent experiments using RNA from mutant cells showed that the population of shorter tRNA ${ }^{\text {Cys }}$ in these mutants represented $3 \pm 1 \%$ and the population of mature tRNA ${ }^{\text {Cys }}$ represented 97 $\pm 2 \%$ of total tRNA ${ }^{\text {Cys }}$ detected by Northern blot analysis. In contrast, quantitative analysis of data from at least three independent experiments showed that in the strain with $c c a$ pnpA mutations, the population of shorter tRNA ${ }^{\text {Cys }}$ species represented $44 \pm 2 \%$ and the population of mature tRNA ${ }^{\text {Cys }}$ represented $56 \pm 2 \%$ of total tRNA ${ }^{\text {Cys }}$ (Fig. 1, left panel and supplementary data). In the single mutant Pspac:rnz or when combined with the cca mutation and in the presence or absence of IPTG, only a major population of mature tRNA ${ }^{\text {Cys }}$ was observed and the population of shorter $\mathrm{tRNA}^{\mathrm{Cys}}$ was not detected (Fig. 1, right panel). We believe that in the absence of RNase Z, the tRNA ${ }^{\text {Cys }}$ can be processed by an exonucleolytic pathway (see further below). We have not yet isolated the two RNA bands from gels to confirm their identities, but the fact that the unique band in the wt strain, which represents the major population of $\mathrm{tRNA}^{\mathrm{Cys}}$, is the only species that reacts with the tRNA ${ }^{\text {Cys }}$-specific probe makes it a near certainty that this species is mature tRNA ${ }^{\mathrm{Cys}}$. It is also reasonable to conclude that the smaller species which accumulates in the absence of $c c a$ is most likely an immature tRNA ${ }^{\text {Cys }}$.

In the $\operatorname{trn} D$ operon, downstream of the $\mathrm{tRNA}^{\mathrm{Cys}}$ gene and separated by seven nucleotides ( $5^{\prime}$ TCTTATT3') is a tRNA ${ }^{\text {Leu }}$ gene, which is followed by a spacer region and finally a transcription terminator. It seemed possible that RNase P could cleave the precursor bearing these tRNAs at the $5^{\prime}$ end of tRNA $^{\text {Leu }}$, thus generating a $3^{\prime}$ extension to $\mathrm{tRNA}^{\mathrm{Cys}}$. Alternatively, that extension might be absent if the intermediate generated by RNase $\mathrm{P}$ is processed further by RNase $\mathrm{Z}$ cleavage at the $3^{\prime}$ end of tRNA ${ }^{\text {Cys }}$. We examined these possibilities by qualitative RT-PCR (Fig. 2, upper diagram). The RT-PCR strategy is based on the ligation of a hybrid RNADNA oligonucleotide to the $3^{\prime}$ end of total RNA and subsequent PCR amplification with a gene-specific oligonucleotide for tRNA ${ }^{\text {Cys }}$ (primer C) and an oligonucleotide complementary to the adaptor (primer A) or with additional nucleotides (5'AATA3') that allow the detection of $3^{\prime}$ extensions (primer B). The RT-PCR results with primers A and C show an amplification product of ca. $100 \mathrm{bp}$ from RNA from the wt strain, which results represent a control for the ligation reactions and for the specificity of the RT-PCR for processed tRNA ${ }^{\text {Cys }}$ (Fig. 2, lane 5). A faint RT-PCR band, presumably representing the
Fig. 1 Analysis of tRNA ${ }^{\text {Cys }}$ processing by Northern blotting in wild type, $c c a$ and exonuclease mutant strains. The lack of or addition of IPTG for induction of RNase $\mathrm{Z}$ expression is indicated as $(+)$ or $(-)$ in the wild type (wt) and $c c a$ mutant strains. Sizes (nt) of the marker bands (Ambion, Decade Marker) are indicated. $5 \mathrm{~S}$ rRNA was used as control for RNA loading in Northern blot analyses. The mature and shorter tRNA $^{\text {Cys }}$ products are indicated with an arrow
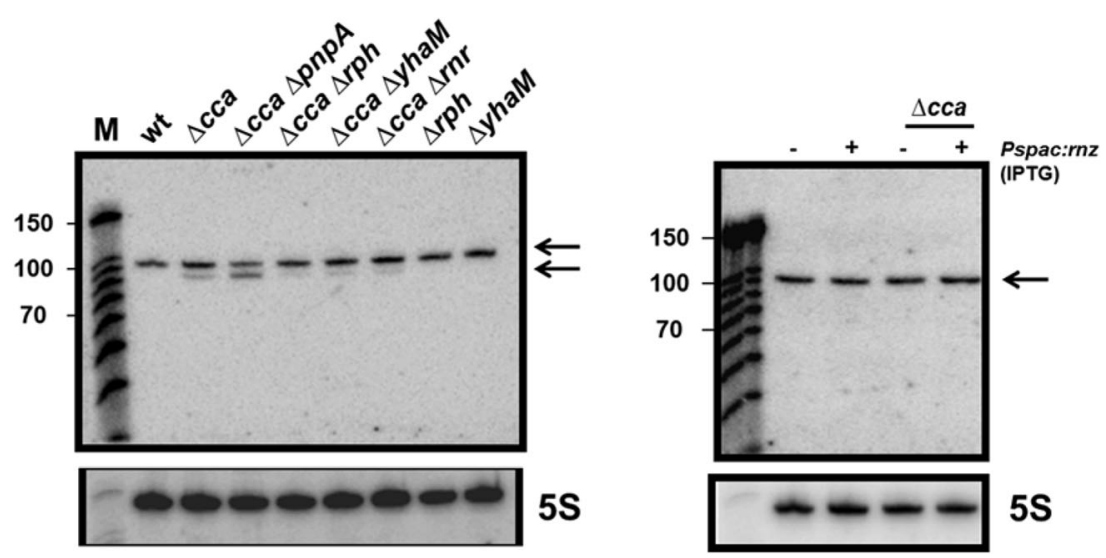


\section{RT-PCR strategy for 3' extension}
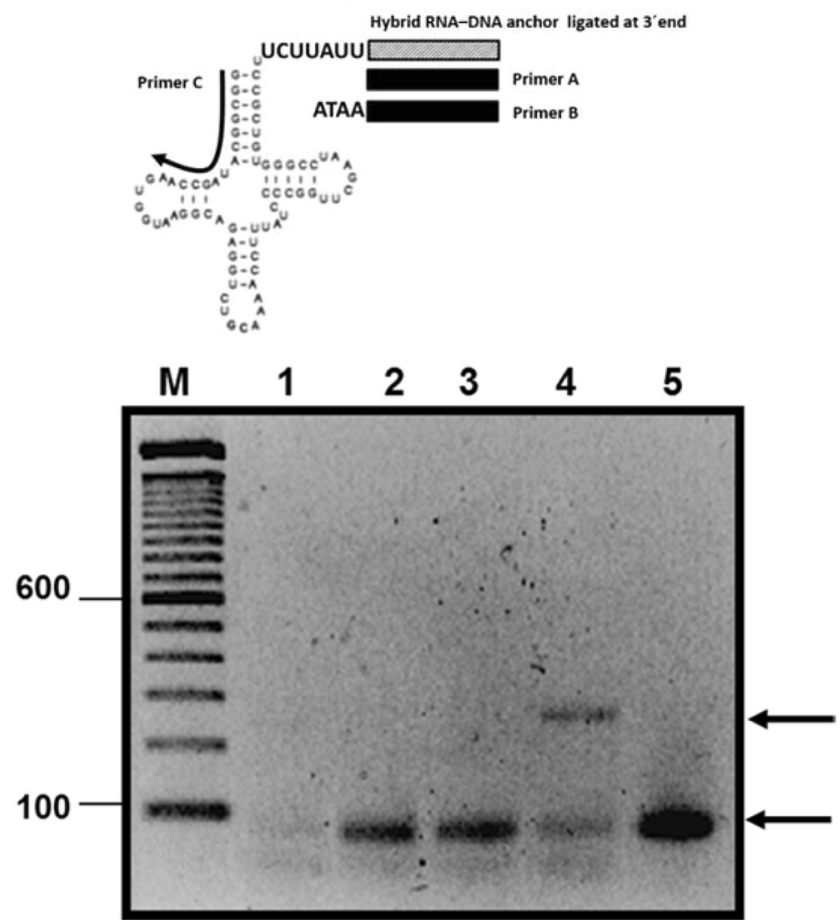

Fig. 2 RT-PCR strategy for examining possible $3^{\prime}$ extensions on tRNA $^{\text {Cys }}$. RT-PCR analysis with primers $\mathrm{B}$ and $\mathrm{C}$ allows the detection of $3^{\prime}$ extensions on tRNA ${ }^{\text {Cys }}$ (upper panel). The agarose gel (lower panel) shows the RT-PCR products obtained with primers B and C, indicated by arrows obtained with wt (lane 1), cca (lane 2), cca pnpA (lane 3), and Pspac:rnz (lane 4) and the RT-PCR product obtained with primers A and $\mathrm{C}$ with wt RNA as control (lane 5). A 100 bp DNA marker was used

$3^{\prime}$ extension in the wild-type strain was observed when primers $\mathrm{B}$ and $\mathrm{C}$ were used (Fig. 2, lane 1). This faint band presumably represents the $3^{\prime}$ extension product resulting from RNase P cleavage of the tRNA ${ }^{\text {Cys }}$-tRNA ${ }^{\text {Leu }}$ precursor. This observation suggests that the species containing the $3^{\prime}$ extension, once formed is rapidly degraded by an exonucleolytic pathway, but also the possibility that this precursor might also undergo processing by an endonucleolytic mechanism involving RNase Z.

When RT-PCR was performed using RNA from the $c c a$ mutant strain, a significantly higher level of the species bearing the putative $3^{\prime}$ extension was observed as compared with the wild-type strain (Fig. 2, lane 2). A similar putative 3' extension product was also observed in the cca pnp double (Fig. 2, lane 3). Thus, the absence of CCAase has an impact on the level of the putative $3^{\prime}$ extension product. When the RTPCR was performed using RNA from the strain Pspac:rnz, uninduced with IPTG, two products of amplification were obtained, one of ca. $100 \mathrm{bp}$, similar to the size observed in the other strains studied, and a second amplification product of ca. $300 \mathrm{bp}$. This larger product was cloned and sequenced, which identified the product as an amplified tRNA ${ }^{\mathrm{Cys}}$ tRNA $^{\text {Leu }}$ precursor; the hybrid RNA-DNA anchor oligonucleotide was ligated at position 205 of the downstream region
Table 1 Clones with $3^{\prime}$ end additions at position 71 on $\mathrm{tRNA}^{\text {Cys }}$ obtained from $c c a$ and $c c a$ pnpA mutant strains

\begin{tabular}{ll}
\hline Strain & 3' end additions \\
\hline cca & GUCGCCU $_{71}$ CCA \\
& GUCGCCU $_{71}$ CCAAA \\
cca pnpA & GUCGCCU $_{71}$ CC \\
& GUCGCCU $_{71}$ CCA \\
& GUCGCCU $_{71}$ CCAAA
\end{tabular}

The bold letters means additional changes presents at the 3 'end of tRNAcys at 71 position, these changes (bold) are very important

(...UUUGUGUU $\left.{ }_{205}\right)$. Thus, a small portion of tRNA ${ }^{\mathrm{Cys}}$ tRNA ${ }^{\mathrm{Leu}}$ precursor is processed by $\mathrm{RNase} \mathrm{Z}$ and in its absence the precursor accumulates. These results show that tRNA ${ }^{\mathrm{Cys}}$ is processed not only by an exonucleolytic pathway but also by an endonucleolytic pathway.

We generated a collection of 24 clones obtained by RTPCR with primers $\mathrm{A}$ and $\mathrm{C}$ that contained fragments of tRNA $^{\text {Cys }}$ of different lengths from $c c a$ and cca pnpA mutant strains to determine the nature of the $3^{\prime}$ ends in those strains. We report below only those results representing $3^{\prime}$ end additions at position 71 (Table 1 and supplementary data). For the cca mutant, we observed 5 clones with complete CCA addition at the $3^{\prime}$ end, but also 2 clones with additional residues, CCAAA, while for the cca pnpA mutant strain we observed 3

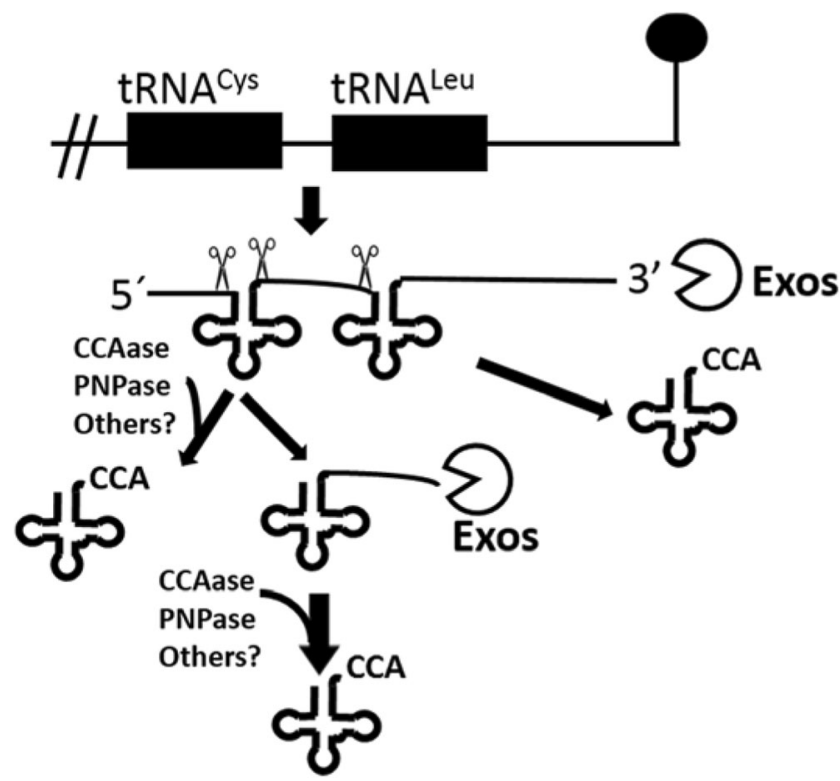

Fig. 3 Model for $3^{\prime}$ maturation of tRNA ${ }^{\text {Cys }}$ in B. subtilis. In the maturation, two pathways are shown; one of them utilizes RNase Z, which cleaves at the $3^{\prime}$ end of tRNA ${ }^{\text {Cys }}$ and RNase P, which cleaves at the $5^{\prime}$ end of tRNA ${ }^{\text {Cys }}$ (scissors). Then, the CCA sequence is added by CCAase, PNPase, or others enzymes. In the second pathway, RNase P cleaves the $5^{\prime}$ end of tRNA ${ }^{\mathrm{Cys}}$ and tRNA ${ }^{\mathrm{Leu}}$, thus generating a $3^{\prime}$ extension to tRNA ${ }^{\text {Cys }}$. Then, the $3^{\prime}$ extension is degraded by exonucleases (PacMan symbol; Exos), followed by maturation or repair by CCAase, PNPase, or others enzymes. The maturation of tRNA ${ }^{\text {Leu }}$ may involve an exonucleolytic pathway 
clones with -CC, 4 clones with CCA, and 1 clone with CCAAA residues.

The studies reported here and our earlier results [1] show that while CCAase is clearly involved in the maturation of tRNA $^{\text {Cys }}$, in its absence a significant level of correct maturation of tRNA ${ }^{\mathrm{Cys}}$ is still possible. As in E. coli, B. subtilis utilizes alternative routes for the maturation and repair of immature and defective tRNA molecules. Enzymes previously implicated in processing immature tRNA ${ }^{\mathrm{Cys}}$ are RNase $\mathrm{R}$ and PNPase, and we note that in our earlier report the data also suggested that the shorter tRNA ${ }^{\text {Cys }}$ species accumulated in the absence of CCAase and RNase R [1].

In our earlier report, we did not observe accumulation of the shorter tRNA ${ }^{\mathrm{Cys}}$ species when PNPase and CCAase were absent [1] from B. subtilis but we did observe that species in the experiments shown here in Fig. 1. We are unsure of the precise explanation for this apparent discrepancy but note that specific features or the genetic background of the mutant strains in different experiments might be contributing factors to the difference between our earlier results and those reported here. We could not, for example, generate the cca pnpA rnr triple mutant. This suggests that this combination is lethal and that interactions between the three enzymes may be responsible for this lethality. A role for both PNPase and RNase R in tRNA $^{\text {Cys }}$ maturation is also suggested by our studies on tRNA ${ }^{\text {Cys }}$ maturation under conditions of oxidative stress [6].

The results reported here thus suggest that PNPase can participate in some pathway for the degradation, maturation, or repair of tRNA ${ }^{\mathrm{Cys}}$ in the absence of CCAase. How might PNPase and RNase $\mathrm{R}$ participate in the processing of immature tRNA ${ }^{\mathrm{Cys}}$ ? Both of these enzymes are exonucleases. It is possible that RNase $\mathrm{R}$ simply recognizes the immature tRNA $^{\text {Cys }}$ as an aberrant product and degrades it. PNPase might play a similar role, but is also known that PNPase can function as an RNA 3'-polynucleotide polymerase, and that unlike poly(A) polymerase, PNPase can utilize all four nucleoside diphosphates to synthesize RNA 3' tails $[12,13]$. Thus, the polymerizing activity of PNPase could make a substantial contribution to the maintenance of the tRNA ${ }^{\mathrm{Cys}}$ population, by adding Cs and/or As to the $3^{\prime}$ ends of immature species.

It is also possible that there are enzymes with $3^{\prime} \mathrm{C}$ and $\mathrm{A}$ adding activity that have yet to be identified. The results shown in Table 1 are consistent with this interpretation. Sequencing results for clones obtained for tRNA ${ }^{\mathrm{Cys}}$ in the absence of CCAase and PNPase suggest that one or more other enzymes capable of adding a C/A-rich tail could be involved in the maintenance of cellular levels of mature tRNA $^{\text {Cys }}$ (Tables 1 and S1). In E. coli for example, a second pathway for tRNA end repair obtains in the absence of CCAase; this route utilizes poly $(\mathrm{A})$ polymerase to incorporate multiple AMP residues into tRNA-C-C and PNPase to remove extra residues as necessary. PNPase may also participate in the synthetic phase of the repair process [13].
In sum, our results are most consistent with a model (Fig. 3) where both endo- and exonucleotlytic pathways are able to generate mature tRNA ${ }^{\text {Cys }}$. The model posits the existence of at least two pathways for the generation of mature tRNA ${ }^{\mathrm{Cys}}$. In one pathway, RNase $\mathrm{Z}$ generates a tRNA ${ }^{\mathrm{Cys}}$ precursor by cleavage at the $3^{\prime}$ end of tRNA ${ }^{\mathrm{Cys}}$ in the intermediate bearing both tRNAs and the resulting CCA-less tRNA ${ }^{\mathrm{Cys}}$ would be rapidly converted to the mature form by CCAase or other enzymes so that the intermediate does not accumulate to a significant extent (Fig. 3, lane 1). In the absence of RNase $\mathrm{Z}$, a short-lived tRNA ${ }^{\mathrm{Cys}}$-tRNA ${ }^{\mathrm{Leu}}$ precursor is formed which is subsequently cleaved by RNAse $\mathrm{P}$. This cleavage produces tRNA ${ }^{\text {Cys }}$ with a $3^{\prime}$ extension and this product accumulates because RNase $\mathrm{Z}$ is absent and CCAase cannot process this intermediate (Fig. 3, lane 4).

The second pathway utilizes RNase $\mathrm{P}$ to cleave the $5^{\prime}$ end of tRNA ${ }^{\text {Leu }}$, thus generating a $3^{\prime}$ extension to tRNA ${ }^{\text {Cys }}$. The $3^{\prime}$ extension is rapidly removed via an exonucleolytic pathway and CCAase, PNPase and perhaps other enzymes can convert this precursor to mature tRNA ${ }^{\text {Cys }}$ by adding the $3^{\prime} \mathrm{CCA}$. In the absence of CCAase, the $3^{\prime}$ extension product accumulates (Fig. 3, lane 2). A probably explanation is that CCAase can work together with some exonucleolitic enzymes to eliminate tRNA ${ }^{\text {Cys }} 3^{\prime}$ extension.

The role of PNPase in our model may be explained in terms of its function in the tRNA ${ }^{\mathrm{Cys}}$ end repair process. For example, the significant accumulation of the shorter tRNA ${ }^{\mathrm{Cys}}$ species in a double mutant (сcа pnpA) suggests that the functions of CCAase and PNPase converge in some common process to maintain the populations of mature tRNA ${ }^{\text {Cys }}$. Further work will be required to clarify these various roles in the maturation of tRNAs with or without an encoded CCA in B. subtilis.

\section{Compliance with ethical standards}

Conflict of interest The authors declare that they have no conflict of interest.

\section{References}

1. Campos-Guillén J, Arvizu-Gómez JL, Jones GH, Olmedo-Alvarez $\mathrm{G}$ (2010) Characterization of tRNA ${ }^{\text {Cys }}$ processing in a conditional Bacillus subtilis CCase mutant reveals the participation of RNase $\mathrm{R}$ in its quality control. Microbiology 156:2102-2111

2. Vold B (1985) Structure and organization of genes for transfer ribonucleic acid in Bacillus subtilis. Microbiol Rev 49(1):71-80

3. Pellegrini O, Nezzar J, Marchfelder A, Putzer H, Condon C (2003) Endonucleolytic processing of CCA-less tRNA precursors by RNase Z in Bacillus subtilis. EMBO J 22(17):4534- 4543

4. Wen T, Oussenko IA, Pellegrini O, Bechhofer DH, Condon C (2005) Ribonuclease PH plays a major role in the exonucleolytic maturation of CCA-containing tRNA precursors in Bacillus subtilis. Nucleic Acids Res 33(11):3636-3643 
5. Campos-Guillén J, Jones GH, Saldaña Gutiérrez C et al (2017) Critical minireview: the fate of tRNACys during oxidative stress in Bacillus subtilis. Biomolecules 7(1):6

6. Cruz Hernández A, Sánchez Millan E, Romero Gómez S et al (2013) Exposure of Bacillus subtilis to mercury induces accumulation of shorter tRNA ${ }^{\text {Cys }}$ species. Metallomics 5(4):398-403

7. Campos-Guillén J, Bralley P, Jones GH, Bechhofer DH, OlmedoAlvarez G (2005) Addition of poly(A) and heteropolymeric 3' ends in Bacillus subtilis wild-type and polynucleotide phosphorylasedeficient strains. J Bacteriol 187(14):4698-4706

8. Wang W, Bechhofer DH (1996) Properties of a Bacillus subtilis polynucleotide phosphorylase deletion strain. J Bacteriol 178(8): 2375-2382

9. Oussenko IA, Abe T, Ujiie H, Muto A, Bechhofer DH (2005) Participation of $3^{\prime}$-to- $5^{\prime}$ exoribonucleases in the turnover of Bacillus subtilis mRNA. J Bacteriol 187(8):2758-2767
10. Oussenko IA, Sanchez R, Bechhofer DH (2002) Bacillus subtilis YhaM, a member of a new family of 3'-to-5' exonucleases in grampositive bacteria. J Bacteriol 184(22):6250-6259

11. Yansura DG, Henner DJ (1984) Use of the Escherichia coli lac repressor and operator to control gene expression in Bacillus subtilis. Proc Natl Acad Sci U S A 81:439-443

12. Mohanty BK, Kushner SR (2000) Polynucleotide phosphorylase functions both as a $3^{\prime}-5^{\prime}$ exonuclease and a poly(A) polymerase in Escherichia coli. Proc Natl Acad Sci U S A 97:11966-11971

13. Reuven NB, Zhou Z, Deutscher MP (1997) Functional overlap of tRNA nucleotidyltransferase, poly(A) polymerase I, and polynucleotide phosphorylase. J Biol Chem 272(52):33255-33259

Publisher's note Springer Nature remains neutral with regard to jurisdictional claims in published maps and institutional affiliations. 